Research Square

\title{
Predictors of neonatal mortality in Ghana: evidence from 2017 Ghana Maternal Health Survey
}

\author{
Emmanuel Ayire Adongo \\ World Child Cancer \\ John Kuumuori Ganle ( $\boldsymbol{\nabla}$ jganle@ug.edu.gh ) \\ University of Ghana
}

\author{
Research Article \\ Keywords: neonatal mortality, predictors, antenatal care, kangaroo mother care, Ghana \\ Posted Date: November 19th, 2021 \\ DOI: https://doi.org/10.21203/rs.3.rs-1051118/v1 \\ License: (c) (i) This work is licensed under a Creative Commons Attribution 4.0 International License. Read Full License
}




\section{Abstract \\ Background}

Neonatal mortality contributes about $45 \%$ of under-5 mortality globally; $35 \%$ in Sub-Saharan Africa; and over $50 \%$ of under-5 deaths in Ghana. Though there are existing studies on the determinants of neonatal mortality in Sub-Saharan Africa, limited population level analysis has been done in Ghana to understand the factors affecting neonatal mortality.

\section{Objectives}

The objective of the study was to examine the predictors of neonatal mortality in Ghana.

\section{Method}

Data from the 2017 Ghana Maternal Health Survey (GMHS) were analysed. The data used in the analysis included only responses from women who delivered live babies in the five years preceding the 2017 GMHS and the children lived for at least 28 days. A total of 10,624 respondents were included in the study after data cleaning. Descriptive statistical techniques (frequency and percentage distribution) were used to describe important background characteristics of the women included in the study. Pearson's Chi-squares $\left(\chi^{2}\right)$ test was used to assess association between the outcome (neonatal death) and independent variables. Multivariate logistic regression analysis was done to estimate odds ratios and control for potential confounders. Confidence level was held at $95 \%$, and a $p<0.05$ was considered statistically significant. All the data analysis was done using STATA 15.

\section{Results}

The prevalence of neonatal mortality was $1.8 \%$ i.e. 18 per 1000 live births. Three factors predicted neonatal mortality: ANC attendance, sex of baby, and baby being put on mother's chest immediately after birth. Women with at least one ANC visit were less likely to experience neonatal mortality as compared to women with no ANC visit prior to delivery ( $\mathrm{AOR}=0.11 ; \mathrm{Cl}=0.02-0.56, \mathrm{p}=0.01)$. Baby girls were less likely $(\mathrm{COR}=0.68$; $\mathrm{Cl}=0.48-0.20 ; \mathrm{p}=0.03$ ) to die during the neonatal period as compared to boys and this did not change when potential confounders were controlled for in a multiple logistic regression model $(A O R=0.68, \mathrm{Cl}=0.47-0.98 ; \mathrm{p}=0.04)$. The odds of a baby dying within the neonatal period when a baby was not put on the mother's chest immediately after birth were 2.5 times higher than those who were put on their mother's chest immediately after birth (COR=2.46; $\mathrm{Cl}=1.66-3.65, \mathrm{p}=0.00)$.

\section{Conclusion}

Community level and sociodemographic factors were not significant predictors of neonatal mortality in this study. Rather, neonatal, and maternal characteristics did. Education on the importance of timely and adequate antenatal care should be intensified. Also, targeted social and behaviour change communication emphasizing the importance of immediate skin-to-skin kangaroo mother care to prevent neonatal hypothermia and promote successful breastfeeding should intensified.

\section{Background}

The first 28 days of life are the most delicate period of life for every newborn child. Globally, neonatal mortality constitutes about $47 \%$ of child mortality [1]. While global neonatal morality stood at 18 per 1000 live births in 2017, the African Region recorded 26.7 per 1000 live births [2]. In 2016, close to 3 million newborn deaths occurred, representing about $46 \%$ of all under-five deaths [2]. This means, every day about 7000 newborns died [2]. Most of these deaths occur before end of the first week of life with about 1 million dying within the first 24 hours and close to one million dying within the next six days [2]. In Sub-Saharan Africa, births are often concealed, unnamed, not counted and unaccounted for until about four years [3]. Community beliefs and practices are barriers to early care seeking, and families often resort to traditional medicine if their newborn is sick [4].

In response to the global and African regional call to action on Reproductive, Maternal, Newborn and Child Health (RMNCH), Ghana signed and committed to the "Every Woman Every Child" and the Global “Newborn Action Plan" [5]. In 2015, Ghana launched the Every Woman Every Child and the "A Promise Renewed" as well as a national costed strategy on newborn care to strengthen evidence-based action to accelerate the reduction of neonatal mortality $[2,5]$. Despite Ghana's commitment, neonatal mortality remains an important public health challenge in the 
country. For instance, Ghana recorded 25 neonatal deaths per 1000 live births in 2017, with about $92 \%$ of newborns' deaths occurring before they reach 7 days [6].

Neonatal mortality is influenced by many factors, including geographical location of parents such as provinces, regions, states, and districts [7-15]. Several studies also found that a number of socio-demographic factors are strongly associated with neonatal mortality [7, 10, 16]. These include maternal education, marital status, place of residence, and wealth quintile [7, 17, 18]. Religion has also been found to be associated with neonatal mortality. Neonates whose mothers are affiliated to religious groups have higher survival probabilities as compared with those whose mothers are without any religious affiliation [19]. In some studies, the Islamic religion was found to be associated with lower risk of neonatal mortality though not statistically significant [20]. In several previous studies, mothers older than forty years had higher neonatal deaths compared with mothers less than forty years of age [13]. Also, children from wealthier families stand a better chance of surviving in their earlier years than children from poorer families [21, 22]. In a systematic review and meta-analysis conducted on the impact of antenatal care on neonatal mortality in Sub-Saharan African countries, women who had at least one antenatal care visit had $39 \%$ lower risk of neonatal mortality as compared with women with no prior antenatal care visit $[23,24]$. Women with multiple deliveries have also been found to have higher risk of their newborns dying $[13,25]$. Studies have also shown that neonatal mortality is prevalent in males than females $[9,25-27]$. Finally, infants with fifth and higher birth orders have higher prevalence of neonatal mortality than infants of lower birth orders [9, $10]$.

Although there are existing studies on the determinants of neonatal mortality in Sub-Saharan Africa, very little has been done in Ghana. Examples of studies conducted on neonatal mortality in Ghana include Welaga et al. [25], Kayode et al. [10], Annan \& Asiedu [14] and Afulani [33]. While these studies have provided important insights on neonatal mortality in Ghana, they have either based on localized data or old national level data. For instance, Welaga et al. [25] only focused on why babies die in the first month after birth in northern Ghana. Annan \& Asiedu [14] study on predictors of neonatal deaths in Ghana also focused on only one region -Ashanti Region - using a cross-sectional study data. Afulani's [33] study also focused on whether the quality of antenatal care mattered in determining neonatal death. Similarly, Kayode et al. [10] multi-level analytical study, which described individual and community level factors influencing neonatal mortality in Ghana, used data from the 2003 and 2008 Ghana Demographic and Health Survey. Besides, Given the SDG 3 target of 12 neonatal deaths per 1000 live births by 2030 , not only is there a need to intensify efforts to further reduce neonatal deaths, but there is also a need for increased research using population level data to fully understand the causes and determinants of neonatal mortality in Ghana, and the strategies need to accelerate progress. It is for this reason that this study aimed to examine the factors influencing neonatal mortality in Ghana as part of efforts to support policies and strategies on accelerating the reduction of neonatal mortality in the country.

\section{Materials And Methods Study design}

This study is an analysis of secondary data from the 2017 Ghana Maternal Health Survey (GMHS). The GMHS is a retrospective crosssectional study, conducted by the Ghana Statistical Service (GSS) and partners [6]. The GMHS survey focuses on population and household characteristics, health, nutrition and lifestyle with particular emphasis on topics that affect the lives of children and women, including mortality levels, fertility preferences and family planning methods [28].

\section{Study Context}

The data used for this studied covered all the 10 old administrative regions of Ghana. Ghana is a West African country with an estimated 30.42 million people.13 Ghana is in West Africa, just above the Equator with a projected population of 30.8Million [29]. Females constitute approximately $50.7 \%$ of the population [29]. Majority of the population (71\%) profess Christianity. While the number of people living below the poverty line has declined over the years, people living in rural regions of Ghana especially in the northern part of the country are getting worse with over $60 \%$ living below the poverty line of GHS 1,314.00 [30]. In terms of healthcare delivery, data from the 2017 Demographic and Health Information Management System (DHIMS 2) shows that Ghana had teaching hospitals (4), regional hospitals (353), district hospitals (140), Psychiatric hospitals (3), 346 Maternity Homes, 38 polyclinics, 1004 health centres, 998 clinics, and 5421 CHPS (community-based health and planning service) compounds, which provide preventive, curative and rehabilitative services to the population [31]. Notwithstanding the availability of these health facilities, Ghana continue to experience significant challenges in implementing proactive interventions to improve newborn survival.

\section{Study population}

The study population comprised women aged 15-49 years who delivered within 5 years preceding the 2017 GMHS [6]. In terms of inclusion criteria, the data used in the analysis included only responses from women who delivered live babies in the five years preceding the conduct of the 2017 Ghana Maternal Health Survey and the children lived for at least 28 days.

Page $3 / 15$ 


\section{Sample size}

In the 2017 GMHS, 25,062 mothers agreed and provided information on the outcome of their births. A total of 15,371 mothers reported having live births in the 5 years preceding the 2017 GMHS. However, a total of 10,624 records were included in this study after cleaning the dataset. The total sample size for this study was thus 10,624.

\section{Sampling method}

The GMHS used a multistage sampling procedure in selecting the study participants [6]. The first stage involved simple random sampling of clusters consisting of enumeration areas (EAs) across the country. Overall, 1,900 enumeration areas (EA) were selected - 466 in urban and 434 in rural areas [6]. The second stage of sampling involved a systematic sampling of households within the clusters [6]. A total of 26,324 households within the selected clusters were sampled out of which 25,062 women aged 15-49 were selected [6]. This was done for the then 10 administrative region of Ghana. The sampling frame adopted the 2010 Population and Housing Census (PHC), which contained all enumeration areas (EAs) that covered about 161 households [6].

\section{Data source and description}

The two main data sources for this study were the Household Questionnaire and the Woman's Questionnaire. The GMHS adapted the Household and Woman's Questionnaire from the DHS Programme's Standard Demographic and Health Survey questionnaires used in the 2007 GMHS to reflect the specific interest of the survey [6]. The Household Questionnaire was used to list all members and visitors, take basic demographic information including age, sex, marital status, education, and relationship to head of the household. The Woman's Questionnaire was used to collect information from women aged 15-49 years. The information collected included background characteristics, pregnancy history (live births, stillbirths, miscarriage, abortion), family planning, pregnancy and postnatal care, abortion, and miscarriage.

\section{Data processing and management}

The Children's folder (GHCH7IFL) was identified as the primary dataset where most of the variables for this study were found. The individual women folder (GHIQ7IFL) was also identified for variables for maternal education, religion, and wealth quintile. This was merged with the primary dataset (Children's folder).

To ensure representativeness of the sample in the various clusters and regions, analyses were performed by weighting the samples according to the sampling weight in the 2017 GMHS dataset by using the 'svy'command in Stata.

\section{Study variables}

\section{Dependent variable}

The dependent variable of interest in this study was "age at death (months)" of the most recent deliveries in the last five years preceding the 2017 GMHS, which was a continuous variable in the dataset from zero to 372 days. For this study, the variable "age at death (months)" was categorized into two and the outcome dichotomized into: whether death happened in age of month zero (i.e. 0-28 days) or between age in month one to 372 (i.e. 1 month -12 months). It was recoded as a binary variable as neonatal mortality, and coded as $0=$ if no, and $1=$ if yes).

\section{Independent variables}

A number of variables were identified in the 2017 GMHS dataset as independent variables. Socio-demographic factors included:

1. Maternal age: This is captured in the $2017 \mathrm{GMHS}$ as a continuous variable from 15 to 49 years. For this study, maternal age was recoded as 15-19 years=1, 20-24years $=2,25-29$ years $=3,30-34$ years $=4,35-39$ years $=5,40-44$ years $=6,45-49$ years $=7$.

2. Maternal religion: This was originally recorded as Catholic, Anglican, Methodist, Presbyterian, Pentecostal/charismatic, other Christian, Islam, traditional/spiritualist, no religion, and other. For the purpose of this study, maternal religion was recoded adding all Christian (catholic, Methodist, Presbyterian, Pentecostal/charismatic, other Christian) as Christians=1, Islam=2,

Traditional/spiritualist=traditional=3, no religion=Atheist $=4$.

3. Maternal education: This was originally recorded in the 2017 GMHS as primary, middle school, JSS/JHS, secondary/tech/voc/comm, SSS/SHS/tech/voc/comm, higher. For this study, maternal education was recoded as 1=no formal education, 2=Primary, 3=JSS/JHS/Middle, 4=SSS/SHS/Voc, 5=Tertiary.

4. Wealth index: The level of household income was defined using wealth quintile as a proxy. This was derived from household ownership of assets and goods such as radio sets, television sets and refrigerator, dwelling characteristics, type of source of drinking water, toilet facilities, electricity, wall and floor materials of the house, cooking fuel and means of transport. Each of these assets was assigned a weight generated using principal component analysis and the resulting scores standardized in relation to a normal distribution with a mean of zero and standard deviation of one. Each household was then given a score for each asset and these asset scores were then 
summed up for and divided into quintiles from lowest (1) to highest (5)(GSS, et al, 2018). In this study, these categorizations were maintained. Thus, lowest=1, second=2, middle=3, fourth $=4$, highest $=5$.

Maternal factors that were examined included:

1. Number of antenatal visits: This was originally recorded in the 2017 GMHS as continuous, from 1 to 20 visits during pregnancy and "don't know". For this study, number of women who had no ANC visits was recoded as $0=$ No ANC visit, 1=1-4 ANC visits, 2=>4 ANC visits. The variable "don't know" was dropped for the sake of clarity of analysis and interpretation.

2. Place of delivery was originally recorded as her home, other home, public (i.e. government hospital, public: government health post/CHPS), public (i.e. mobile clinic/outreach, public: other public sector, private: hospital/clinic), private (i.e. FP/PPAG clinic), private (i.e. mobile clinic/outreach), private (i.e. maternity home), private (i.e. other private medical centre), and other. For the purpose of this study, place of delivery was recoded as her home and other home as Home delivery, public: government hospital, public: government health post/CHPS, public: mobile clinic/outreach, public: other public sector as Public Health Facility, private: hospital/clinic, private: FP/PPAG clinic, private: mobile clinic/outreach, private: maternity home, private: other private med centre as Private Health Facilities, and other as Others.

3. Mode of Delivery was originally recorded as delivery by Caesarean Section and recoded as Yes and No. For this study, delivery by Caesarean Section was renamed as mode of delivery and recorded as Yes as C/S, No as Spontaneous Vaginal Delivery.

Newborn factors that were also examined included:

1. Size of child at birth was recorded in the 2017 GMHS as very large, larger than average, average, smaller than average, very small and don't know. For this study, size of child at birth was recoded as very large and larger than average as large=1, average as average $=2$ and smaller than average and very small as small=3. The variable "don't know" was dropped to provide clarity in the data analysis.

2. Sex of baby was recorded in the 2017 GMHS as girl and boy. This was maintained in this study.

3. Child put on mother's chest immediately after birth (i.e. kangaroo mother care) was recorded in the $2017 \mathrm{GMHS}$ as yes, no and don't know. This was recoded for the purpose of this study as 1=yes, 2=no. The variable "don't know" was dropped to provide clarity in the data analysis.

\section{Data analysis}

Descriptive statistical techniques (i.e. frequency and percentage distribution) were used to describe important background characteristics of the women included in the study. In addition, Pearson's Chi-squares $\left(\chi^{2}\right)$ test was used to assess association between the outcome (neonatal death) and the independent variables. Multivariate logistic regression analysis was also done to estimate the odds ratio and control for potential confounders. Confidence level was held at $95 \%$, and a $p<0.05$ was considered statistically significant. All the data analysis was done using STATA 15.

\section{Quality assurance measures}

To ensure data quality, only relevant data set from the DHS programme website were accessed and downloaded. The dataset was examined thoroughly and only relevant information was extracted. We first run frequencies and percentages on all variables to identify patterns and missing data. Variables with missing data and small frequencies for some categories were recoded. The two authors of this paper independently did the recoding. Comparisons were then made, and where there were any differences, a reconciliation was done before analysis. Finally, data quality was ensured by using Stata issued-commands to recode variables into new categories appropriate for the study. A 'Stata Do' file was used throughout the analysis to record all statistical analysis performed. Appropriate changes were made and saved to the Stata Do file when needed after which results were rerun again. This process minimised inconsistencies and ensured data quality.

\section{Results}

\section{Background characteristics of respondents}

Table 1 shows the background characteristics of respondents. The majority (24.6\%) of respondents were aged $25-29$ years. Also, majority of the respondents (51.7\%) resided in rural areas. Over a fifth (24\%) of respondents had no formal education, with less than a tenth (6.2\%) having tertiary education. Majority (77.2\%) of respondents were Christians. Respondents who did not attend antenatal care (ANC) prior to delivery were $2.3 \%$ while $81.3 \%$ attended antenatal care more than 4 times during their most recent pregnancy. As regards place of delivery, $67.2 \%, 11.4 \%$ and $20.3 \%$ delivered in public health facilities, private health facilities, and at home, respectively. Also, $15.8 \%$ had caesarean section deliveries. 
Table 1

Background characteristics of women who had newborn babies in the last 5 years preceding the 2017 GMHS $(n=10,624)$

\begin{tabular}{|c|c|c|}
\hline Characteristics & Number & Percentage \\
\hline \multicolumn{3}{|l|}{ Zone of Residence } \\
\hline Southern & 4787 & 45.1 \\
\hline Middle & 4098 & 38.6 \\
\hline Northern & 1739 & 16.3 \\
\hline \multicolumn{3}{|l|}{ Place of Residence } \\
\hline Urban & 5130 & 48.3 \\
\hline Rural & 5495 & 51.7 \\
\hline \multicolumn{3}{|l|}{ Maternal Age (years) } \\
\hline $15-19$ & 564 & 5 \\
\hline $20-24$ & 1928 & 18 \\
\hline $25-29$ & 2612 & 24.6 \\
\hline $30-34$ & 2498 & 23.5 \\
\hline $35-39$ & 1876 & 17.7 \\
\hline $40-44$ & 849 & 8 \\
\hline $45-49$ & 297 & 2.8 \\
\hline \multicolumn{3}{|l|}{ Maternal Religion } \\
\hline Christian & 8207 & 77.2 \\
\hline Islam & 1851 & 17.4 \\
\hline Traditional & 250 & 2.3 \\
\hline Atheist & 316 & 3 \\
\hline \multicolumn{3}{|l|}{ Maternal Education } \\
\hline No Formal Education & 2552 & 24 \\
\hline Primary & 1875 & 17.6 \\
\hline JSS/JHS & 4209 & 39.6 \\
\hline SHS/SSS & 1330 & 12.5 \\
\hline Tertiary & 658 & 6.2 \\
\hline \multicolumn{3}{|l|}{ Wealth Index } \\
\hline Lowest & 2286 & 21.5 \\
\hline Second & 2304 & 21.7 \\
\hline Middle & 2112 & 20 \\
\hline Fourth & 2097 & 20 \\
\hline Highest & 1825 & 17.2 \\
\hline \multicolumn{3}{|l|}{ Number of ANC visits } \\
\hline None & 241 & 2.3 \\
\hline 1 & 141 & 1.3 \\
\hline $2-4$ & 1608 & 15.1 \\
\hline
\end{tabular}

Page 6/15 


\begin{tabular}{|lll|}
\hline Characteristics & Number & Percentage \\
\hline$>4$ & 8634 & 81.3 \\
\hline
\end{tabular}

\begin{tabular}{|c|c|c|}
\hline Characteristics & Number & Percentage \\
\hline \multicolumn{3}{|l|}{ Place of Delivery } \\
\hline Home & 2159 & 20.3 \\
\hline Public Health Facility & 7135 & 67.2 \\
\hline Private Health Facility & 1208 & 11.4 \\
\hline Others & 122 & 1.1 \\
\hline \multicolumn{3}{|l|}{ Mode of Delivery } \\
\hline Caesarean Section & 1277 & 15.8 \\
\hline Spontaneous Vaginal Delivery & 9347 & 84 \\
\hline \multicolumn{3}{|l|}{ Size of Baby at birth } \\
\hline Large & 4437 & 41.2 \\
\hline Average & 4264 & 40.1 \\
\hline Small & 1923 & 18.1 \\
\hline \multicolumn{3}{|l|}{ Sex of baby } \\
\hline Boy & 5375 & 50.6 \\
\hline Girl & 5249 & 49.4 \\
\hline \multicolumn{3}{|c|}{ Child put on mother's chest immediately after birth } \\
\hline Yes & 5254 & 49.5 \\
\hline No & 5370 & 50.4 \\
\hline
\end{tabular}

\section{Prevalence of neonatal mortality}

Out of the 10,624 respondents who reported to have delivered livebirths within the 5 years preceding the 2017 GMHS, 190 newborns died within the first 28 days of life. This represents a neonatal mortality prevalence of $1.8 \%$ or $18 / 1000$ livebirths.

\section{Predictors Of Neonatal Mortality}

Table 2 presents bivariate analysis examining association between neonatal mortality and community level, socio-demographic, maternal and neonatal factors. None of the community level factors were associated with neonatal mortality: Zone of residence $(p=0.26)$, and place of residence $(p=0.51)$. Similarly, none of the socio-demographic factors examined showed statistical association with neonatal mortality: maternal age $(p=0.93)$; maternal religion $(p=0.70)$; maternal education $(p=0.34)$; and wealth index $(p=0.81)$. Among three maternal factors examined, number of ANC visits was statistically significantly associated with neonatal mortality $(p<0.001)$. However, place of delivery $(p=0.80)$, and mode of delivery $(p=0.25)$ were not statistically significant associated with neonatal mortality. Out of the three neonatal variables examined, two were statistically significantly associated with neonatal mortality. These were sex of the baby $(p=0.03)$ and child put on mother's chest immediately after birth $(p=0.00)$. Though size of the baby was not statistically significant $(p=0.07)$, it was very important as a potential determinant of neonatal mortality. 
Table 2

Factors associated with neonatal death (bivariate analysis) $(n=10,624)$

\begin{tabular}{|c|c|c|c|}
\hline \multirow[t]{2}{*}{ Characteristics } & \multicolumn{2}{|c|}{ Neonatal Mortality } & \multirow[t]{2}{*}{ P-value } \\
\hline & No, n (\%) & Yes, n (\%) & \\
\hline \multicolumn{4}{|l|}{ Place of Residence } \\
\hline Urban & $5044(98.3)$ & $86(1.7)$ & \multirow[t]{2}{*}{0.51} \\
\hline Rural & $5390(98.1)$ & 104(1.9) & \\
\hline \multicolumn{4}{|l|}{ Zone of settlement } \\
\hline Southern & 4690(98) & $97(2.0)$ & \multirow[t]{3}{*}{0.26} \\
\hline Middle & $4029(98.3)$ & $69(1.7)$ & \\
\hline Northern & 1715(98.6) & $24(1.4)$ & \\
\hline \multicolumn{4}{|c|}{ Maternal Age (completed years) } \\
\hline $15-19$ & $552(97.9)$ & $12(2.1)$ & \multirow[t]{7}{*}{0.93} \\
\hline $20-24$ & 1898(98.5) & $30(1.5)$ & \\
\hline $25-29$ & 2571(98.4) & $41(1.6)$ & \\
\hline $30-34$ & 2449(98.1) & $49(1.9)$ & \\
\hline $35-39$ & 1840(98.1) & $36(2.1)$ & \\
\hline $40-44$ & $832(98)$ & $17(2)$ & \\
\hline $45-49$ & 291(98.2) & $6(1.8)$ & \\
\hline \multicolumn{4}{|l|}{ Maternal Religion } \\
\hline Christian & $8060(98.2)$ & $147(1.8)$ & \multirow[t]{4}{*}{0.70} \\
\hline Islam & 1819(98.3) & $32(1.7)$ & \\
\hline Traditional & $247(98.7)$ & $3(1.2)$ & \\
\hline Atheist & $307(97.2)$ & $9(2.8)$ & \\
\hline \multicolumn{4}{|l|}{ Maternal Education } \\
\hline No Formal Education & $2514(98.5)$ & $38(1.5)$ & \multirow[t]{5}{*}{0.34} \\
\hline Primary & 1836(97.9) & $39(2.1)$ & \\
\hline JHS/JSS/Middle & 4136(98.3) & 73(1.7) & \\
\hline SHS/SSS/Vocational & $1295(97.4)$ & $35(2.7)$ & \\
\hline Tertiary & $651(99.0)$ & $7(1.0)$ & \\
\hline \multicolumn{4}{|l|}{ Wealth Index } \\
\hline Lowest & $2242(98.1)$ & $44(1.9)$ & \multirow[t]{5}{*}{0.81} \\
\hline Second & 2263(98.2) & $41(1.8)$ & \\
\hline Middle & 2072(98.1) & $40(1.9)$ & \\
\hline Fourth & 2056(98.0) & $41(1.9)$ & \\
\hline Highest & 1801(98.7) & $24(1.3)$ & \\
\hline \multicolumn{4}{|l|}{ Number of ANC visits } \\
\hline None & $227(94.2)$ & $14(5.8)$ & \multirow[t]{2}{*}{$0.00 * \star$} \\
\hline 1 & $140(99.3)$ & $1(0.7)$ & \\
\hline${ }^{\star} P<0.05 ; * \star p<0.01$ & & & \\
\hline
\end{tabular}




\begin{tabular}{|c|c|c|c|}
\hline \multirow[t]{2}{*}{ Characteristics } & \multicolumn{2}{|c|}{ Neonatal Mortality } & \multirow[t]{2}{*}{ P-value } \\
\hline & No, n (\%) & Yes, n (\%) & \\
\hline $2-4$ & 1579(98.2) & $29(1.8)$ & \\
\hline$>4$ & $8487(98.3)$ & $147(1.7)$ & \\
\hline \multicolumn{4}{|l|}{ Place of Delivery } \\
\hline Home & 2117(98.1) & $42(1.9)$ & \multirow[t]{4}{*}{0.80} \\
\hline Public Health & $7005(98.2)$ & $130(1.8)$ & \\
\hline Private Health & 1191(98.6) & $17(1.4)$ & \\
\hline Other & $120(98.6)$ & $2(1.4)$ & \\
\hline \multicolumn{4}{|l|}{ Mode of Delivery } \\
\hline Caesarean Section & $1247(97.6)$ & $30(2.3)$ & \multirow[t]{2}{*}{0.25} \\
\hline Spontaneous Vaginal Delivery & 9187(98.3) & $160(1.7)$ & \\
\hline \multicolumn{4}{|l|}{ Sex of baby } \\
\hline Boy & $5261(97.9)$ & $114(2.1)$ & \multirow[t]{2}{*}{$0.03^{\star}$} \\
\hline Girl & $5173(98.6)$ & $76(1.5)$ & \\
\hline \multicolumn{4}{|l|}{ Size of baby at birth } \\
\hline Large & $4360(98.3)$ & $78(1.7)$ & \multirow[t]{3}{*}{0.07} \\
\hline Average & 4192(98.3) & $72(1.7)$ & \\
\hline Small & 1881(97.8) & $41(2.2)$ & \\
\hline \multicolumn{4}{|c|}{ Child put on mother's chest immediately after birth } \\
\hline Yes & $5200(98.9)$ & $54(1.0)$ & $0.00 * \star$ \\
\hline No & $5234(97.5)$ & $136(2.5)$ & \\
\hline$* P<0.05 ; * \star p<0.01$ & & & \\
\hline
\end{tabular}

From the bivariate analysis in Table 2, only three independent variables (i.e. sex of baby, number of antenatal (ANC) attendance and baby put on mother's chest immediately after birth) were statistically associated with neonatal mortality. To further determine the strength of these variables, confounders were controlled for in a multiple regression model and odd ratios were estimated. The results are shown in Table 3.

In a binary logistic regression model, the odds of a woman who had at least 1 ANC visit prior to delivery experiencing neonatal mortality were significantly lower compared those who had no ANC visit prior to delivery ( $\mathrm{COR}=0.27 ; \mathrm{Cl}=0.13-0.68 ; \mathrm{p}=0.00)$. When potential confounders were controlled for in a multiple regression logistic model, women with only 1 ANC visit prior to delivery were still less likely to experience neonatal mortality as compared to women with no ANC visit prior to delivery $(\mathrm{aOR}=0.11 ; \mathrm{Cl}=0.02-0.56, \mathrm{p}=0.01)$. Women with 2-4 ANC visits were also less likely to experience neonatal mortality as compared to women who had no antenatal care ( $\mathrm{COR}=0.27 ; \mathrm{Cl}=0.13-0.68, \mathrm{p}=0.00)$. When potential confounders were controlled for in a multiple regression model, the odds of women experiencing neonatal mortality slightly increased $(\mathrm{aOR}=0.29 ; \mathrm{Cl}=0.12-0.68 ; \mathrm{p}=0.01)$ though still protective as compared to women with no prior antenatal attendance. Also, women with more than 4 antenatal visits were less likely to experience neonatal mortality as compared to women with no antenatal visits prior to delivery $(\mathrm{cOR}=0.28 ; \mathrm{Cl}=0.13-0.60 ; \mathrm{p}=0.00)$. This did not change $(\mathrm{aOR}=0.29 ; \mathrm{Cl}=0.13-0.67 ; \mathrm{p}=0.00)$ when potential confounders were controlled for in a multiple regression model.

In a binary logistic regression, girls were less likely ( $\mathrm{cOR}=0.68 ; \mathrm{Cl}=0.48-0.20 ; \mathrm{p}=0.03)$ to die during the neonatal period as compared to boys and this did not change when potential confounders were controlled for in a multiple logistic regression model ( $\mathrm{cOR}=0.68, \mathrm{Cl}=0.47-0.98$; $p=0.04$ ). Similarly, the odds of a baby dying within the neonatal period when the baby was not put on the mother's chest immediately after birth was 2.5 times higher compared those who were put on the mother's chest immediately after birth ( $\mathrm{COR}=2.46 ; \mathrm{Cl}=1.66-3.65, \mathrm{p}=0.00)$. After controlling for potential confounders in the multiple logistic regression model, the odds slightly increased to 2.6 times, and the association remained statistically significant $(\mathrm{aOR}=2.59 ; \mathrm{Cl}=1.75-3.83 ; \mathrm{p}=0.00)$. 
Table 3

Predictors of neonatal mortality (Binary and Multilevel Regression analysis), $\mathrm{n}=10,624$

\begin{tabular}{|c|c|c|c|c|c|c|}
\hline \multirow[t]{2}{*}{ Characteristics } & \multicolumn{2}{|c|}{ Neonatal Mortality } & \multirow[t]{2}{*}{ cOR[95\%Cl] } & \multirow{2}{*}{$\begin{array}{l}\text { P- } \\
\text { value }\end{array}$} & \multirow[t]{2}{*}{ aOR[95\%Cl] } & \multirow[t]{2}{*}{ P-value } \\
\hline & No, $n(\%)$ & $\begin{array}{l}\text { Yes n } \\
(\%)\end{array}$ & & & & \\
\hline \multicolumn{7}{|c|}{ Number of ANC visits } \\
\hline None (Ref) & & & & 1 & & \\
\hline 1 & 140(99.3) & $1(0.7)$ & $\begin{array}{l}0.11(0.02- \\
0.54)\end{array}$ & $0.01 *$ & $0.11(0.02-0.56)$ & $0.01^{*}$ \\
\hline $2-4$ & 1579(98.2) & $29(1.8)$ & $\begin{array}{l}0.27(0.13- \\
0.68)\end{array}$ & $0.00 * \star$ & $0.29(0.12-0.68)$ & $0.01 *$ \\
\hline$>4$ & 8487(98.3) & $147(1.7)$ & $\begin{array}{l}0.28(0.13- \\
0.60)\end{array}$ & $0.00 * *$ & $0.29(0.13-0.67)$ & 0.00 \\
\hline \multicolumn{7}{|l|}{ Sex of baby } \\
\hline Boy (Ref) & $5261(97.9)$ & $114(2.1)$ & & 1 & & \\
\hline Girl & $5173(98.6)$ & $76(1.5)$ & $\begin{array}{l}0.68(0.48- \\
0.97)\end{array}$ & $0.03^{*}$ & $0.68(0.47-0.98)$ & $0.04^{\star}$ \\
\hline \multicolumn{7}{|c|}{$\begin{array}{l}\text { Child put on mother's chest immediately after } \\
\text { birth }\end{array}$} \\
\hline Yes (Ref) & $5200(98.9)$ & $54(1.0)$ & & 1 & & \\
\hline No & $5234(97.5)$ & $136(2.5)$ & $\begin{array}{l}2.46(1.66- \\
3.65)\end{array}$ & $0.00 * *$ & $2.59(1.75-3.83)$ & $0.00 * \star$ \\
\hline
\end{tabular}

\section{Discussion}

This study found that the prevalence of neonatal mortality in a nationally representative sample of 10,624 livebirths was $1.8 \%$, expressed as 18 per 1000 live births. Though this is lower than the 2017 GMHS rate of 25 per 1000 live births, it is still far higher than the SDG 3 target of 12 per 1000 live births by 2030 (United Nations, 2015). It is therefore important to strengthen interventions to accelerate reduction of neonatal mortality through the use of evidence-based solutions and cost-effective interventions that have been proven to reduce neonatal mortality in LMICs including Essential Newborn Care (ENC), Kangaroo Mother Care (KMC), breastfeeding, Focus Antenatal care and administration of antenatal corticosteroid [32].

The results of this study support findings from previous studies that showed that having antenatal care prior to delivery improves neonatal outcomes $[23,24]$. It is however important to note that the results of this study did not show that having more antenatal care visits improve neonatal outcome per se. It is not entirely clear why this is the case, and there is a need to carry out further studies to examine the relationship between number of antenatal care visits and the effect on neonatal mortality in Ghana. This said, there are several reasons why ANC attendance may lower the risk of neonatal mortal. For instance, during ANC visits, women are checked (e.g. blood pressure, pulse, foetal pulse, blood chemistry), counselled on maternal and foetal risk factors, diet, exercise, rest and well as given vitamin supplements, immunized against tetanus diphtheria, given dewormers, as well as having foetal growth and presentation checked (WHO, 2016). Thus, while the number of antenatal visits made may not necessarily result in improved maternal and neonatal outcomes because of the quality of the service package [33], ANC attendance may ensure that risk factors are identified and resolved early to improve maternal and foetal outcomes [34]. It is for this reason that the WHO recently recommended at least eight antenatal visits for pregnant women - an increase from the previously recommended four visits [34]. While increasing the number of antenatal care visits may not be of benefit to women in Ghana because of poor quality of antenatal care [33], building the capacity of healthcare providers to provide quality antenatal care could be very essential in ensuring that women benefit from services received from the health system. This calls for the government of Ghana and Ghana Health Service to intensify monitoring and coaching visits to ensure that health service providers are providing client-focused quality antenatal care for women. This will go a long way to improve neonatal outcomes.

Female babies were also less likely to die in the neonatal period compared to their male counter parts: females had $32 \%$ lower odds of neonatal mortality as compared to their male counterparts. In Bangladesh, males infants were 1.4 times more likely to die as compared to their female counterpart during the neonatal period [27].In Northern Ghana, the odds of dying during the first $28 \mathrm{days}$ was 1.2 times in males 
as compared with their female counterparts [25]. We are surprised by this finding. Demographically, females have been found to possess better survival advantages compared to their male counterparts [35]. This has given rise to a better sex ratio in their favour globally. It is therefore not surprising to find similar characteristics in the findings of this study. While it is not entirely clear what accounts for the sex differences in risk of neonatal mortality, some previous studies have linked this difference to genetic and developmental disadvantage of male babies, which is more pronounced following birth [36]. These biological factors are particularly associated with the slow development and maturity of male infant lungs compared to their female counterparts [26, 35]. The relevance of this finding is that it could inform healthcare providers to prepare expectant families of the need to provide gender-based care to ensure that male infants receive the needed care to help them thrive and survive. Also, it is important to create community awareness on sex differentiation in survival rates to improve on their knowledge and practices related to neonatal care.

Findings also revealed that babies who did not benefit from immediate skin-to-skin care were 2.6 times more likely to die when compared to those who benefited. Indeed, the current study is one of the few studies to have assessed the effect of immediate skin-to-skin care on neonatal mortality in Sub-Saharan Africa and will thus support the "warm chain" protocols recommended by WHO as part of basic neonatal resuscitation in LMICs particularly in Ghana [37]. Immediate skin-to-skin care, otherwise known as putting baby on mother's chest immediately after birth, is part of the components of immediate essential newborn care (ENC) [38]. According to the WHO, the first step in saving the life of a baby immediately after birth is to put the baby to the mother's chest immediately the baby is born with a clean cloth [37]. It provides the infant warmth, thereby preventing neonatal hypothermia, which is one of the three major causes of neonatal mortality [39]. The findings of this study thus provide further empirical evidence to support this cost-effective intervention: that putting babies on their mother's chest could provide extra-uterine support to newborns by improving their score on Stability of Cardio-Respiratory system during the first six hours post birth suggestive of better infant stabilisation to extrauterine life, blood glucose levels, and infant thermoregulation [40]. Despite the benefits of this ENC intervention, studies reveal that in LMICs, the practice is poor and most healthcare professionals lack the competence to provide quality ENC services in the midst of inadequate equipment to provide ENC services including inadequate bag and mask [38]. It is therefore important from the foregoing for policy makers, particularly, Ghana's Ministry of Health and Ghana Health Service to strengthen the health system to ensure availability, knowledge and skills on policies on ENC, availability and functional equipment including bag and mask, proficiency of healthcare providers, documentation and improve monitoring and supervision to ensure that quality and client-centred care is provided to improve neonatal outcomes. Community members, family members and opinion leaders should also be sensitised on the relevance of immediate skin-to-skin to prepare themselves before they go into labour.

Finally, this study has a number of limitations. For instance, while several more variables could potentially affect neonatal mortality, reliance on the number of variables available in the 2017 GMHS meant that the analysis was only limited to only 12 independent variables that were measured and fully captured in 2017 GMHS. Also, the design of the study and the reliance on secondary data did not offer an opportunity for exploring reasons that could help understand some of the findings better. Future research could be prospective and use mixed methods to gain better understanding. It is important to acknowledge the fact that errors such as recall bias and social desirability responses could not have been corrected in this study. Therefore, though the results could be important in planning, their application in the general population should be done with caution, taking into consideration, the limitations enumerated. These limitations notwithstanding, the strength of this study included the fact that it had a national character and as a result, the findings could be generalized to the wider population. The study also established a relationship between immediate skin-to-skin and neonatal mortality, which has not been given the needed attention in the provision of empirical evidence to back intervention on ENC. This study has thus added more empirical evidence to the determinants of neonatal mortality in Ghana, and these findings have implications for interventions in neonatal health.

\section{Conclusion}

This study aimed to identify predictors of neonatal mortality in Ghana among women who had live births in the last five years preceding the 2017 GMHS. The study revealed that neonatal mortality was $1.8 \%$ and this is equivalent to 18 neonatal deaths per 1000 live births. The results revealed that community level and sociodemographic factors were not significant predictors of neonatal mortality. Rather, three maternal and neonatal factors (i.e. sex of baby and number of antenatal visits prior to delivery, and baby put on mother's chest immediately after birth (immediate skin-to-skin) were the strongest significant predictors of neonatal mortality in Ghana.

Based on the findings reported and discussions above, it is recommended that the Ministry of Health and Ghana Health Service implement interventions to sensitise women to understand the importance of ANC attendance and the need to start ANC early. In this regard, there is a need to identify and use appropriate social and behaviour change communication (SBCC) strategies through various channels including radios, television, social media and community Public Address System (PAS), community meetings including informal women's and men's groups and networks, as well as scheduled and routine home visits of Community Health Nurses. There is also a need to build the capacity of healthcare providers on quality of antenatal care to ensure that women benefit from not only the quantity of antenatal care but quality as well. Also, ensuring that supervisors at all levels improve on the frequency and quality of supportive visits at all levels could help ensure that quality 
antenatal care is provided. It is also recommended that healthcare providers and women be trained and/ or sensitized to recognize sex differentiation in the risk of neonatal death and how to better support male infants thrive and survive. This would involve building the capacity of healthcare providers and educating communities to ensure that they are aware of the different risks that sex differentiation confers on neonates and the need to provide extra care for male neonates to improve their survival. Finally, it is essential that community knowledge, attitudes, and practices on immediate skin-to-skin care are improved through SBCC using various channels of communication including social media, mass media, community PAS and compound visits. Healthcare workers should also be trained to improve on their knowledge, attitude, and practice. Though this is already ongoing, there is need to intensify efforts through continued capacity building and improved monitoring and supportive supervision.

\section{Abbreviations}

\section{ANC}

Antenatal Care

aOR

adjusted Odds Ratio

CHPS

Community-based Health and Planning Service)

Cl

Confidence Interval

cOR

crude Odds Ratios

DHIMS

Demographic and Health Information Management System

DHS

Demographic and Health Survey

ENC

Essential Newborn Care

GHS

Ghana Health Service

GSS

Ghana Statistical Service

GMHS

Ghana Maternal Health Survey

LMICs

Low- and Middle-Income Countries

$\mathrm{MoH}$

Ministry of Health

PAS

Public Address System

RMNCH

Reproductive, Maternal, Newborn and Child Health

SBCC

Social and Behaviour Change Communication

SDG

Sustainable Development Goal

WHO

World Health Organisation

\section{Declarations}

\section{Ethical Approval and Consent to Participate}

As the data for this study were secondary and anonymized, there was no need for ethical approval. However, permission was sought from the Demographic and Health Surveys (DHS) programme, and a permission/access was granted. Also, all methods and study procedures were performed in accordance with the ethical standards laid down in the 1964 Declaration of Helsinki and its later amendments. 
Not applicable.

\section{Availability of data and materials}

The dataset supporting the conclusions of this article is included within the article

\section{Competing interests}

The authors declare that they have no conflict of interests.

\section{Funding}

None

\section{Authors' contributors}

EAA conceived the study. EAA and JKG designed the study. JKG developed the methods, while EAA performed the data analysis and drafted the initial manuscript. JKG had responsibility for revising the draft manuscript. All authors read and approved the final version. All authors consented to publication of this manuscript.

\section{Acknowledgement}

The authors thank the DHS programme for granting us access to the data.

\section{Authors' Information}

Emmanuel Ayire Adongo is a Faculty Member and Fellow of the Ghana College of Nurses and Midwives. He is also the Regional Coordinator for Sub-Saharan Africa for World Child Cancer.

Dr. John Kuumuori Ganle is a senior lecturer at the Department of Population, Family and Repreductive Health, School of Public Health, University of Ghana

\section{References}

1. World Health Organization. Causes of child mortality, 2018. Retrieved on August 22, 2019, from Who website: http://www.who.int/gho/child_health/mortality/causes/en/

2. World Health Organization. Neonatal mortality, 2017. Retrieved on March 1, 2020, from: https://www.who.int/gho/child_health/mortality/neonatal_text/en/\%0Ahttp://www.who.int/gho/child_health/mortality/neonatal_text/en/

3. Kinney MV, Kerber KJ, Black RE, Cohen B, Nkrumah F, Coovadia H, Lawn JE. Sub-Saharan Africa's mothers, newborns, and children: Where and why do they die? PLoS Medicine, 2010; 7(6). https://doi.org/10.1371/journal.pmed.1000294

4. Lawn J, Blencowe H, Oza, You D, Lee A, Waiswa P. Every Newborn: progress, priorities, and potential beyond survival. The Lancet, 2014; 384(9938).

5. Ministry of Health and Ghana Health Service. Ghana National Newborn Health Strategy And Action Plan, 2019-2023; Accra, 2019.

6. Ghana Statistica Service, Ghana Health Service, ICF. Ghana Maternal Health Survey 2017. Accra, 2018. Retrieved from www.DHSprogram.com.

7. Upadhyay RP, Dwivedi PR, Rai SK, Misra P, Kalaivani M, Krishnan A. Determinants of neonatal mortality in rural Haryana: A retrospective population based study. Indian Pediatrics, 2012; 49(4):291-294. https://doi.org/10.1007/s13312-012-0044-2

8. Msemo G, Massawe A, Mmband D, Rusibamayila N, Manji K, Kidanto HL, Perlman J. Newborn Mortality and Fresh Stillbirth Rates in Tanzania After Helping Babies Breathe Training. Pediatrics, 2013; 131(2), e353-e360. https://doi.org/10.1542/peds.2012-1795

9. Mekonnen Y, Tensou B, Telake DS, Degefie T, Bekele A. Neonatal mortality in Ethiopia: Trends and determinants. BMC Public Health, 2013; 13(1). https://doi.org/10.1186/1471-2458-13-483

10. Kayode GA, Ansah E, Agyepong IA, Amoakoh-Coleman M, Grobbee DE, Klipstein-Grobusch K. Individual and community determinants of neonatal mortality in Ghana: A multilevel analysis. BMC Pregnancy and Childbirth, 2014; 14(1), 165. https://doi.org/10.1186/1471-239314-165 
11. Kayode G, Grobbee D, Amoakoh-Coleman M, Ansah E, Uthman O, Klipstein-Grobusch K. Variation In Neonatal Mortality And Its Relation To Country Characteristics In Sub-Saharan Africa. BMJ Global Health, 2017; 2(Suppl 2):A49.1-A49. https://doi.org/10.1136/bmjgh-2016000260.130

12. Kikuchi K, Okawa S, Yasuoka J, Nanishi K, Shibanuma A, Jimba M, Kamiya Y. Effective linkages of continuum of care for improving neonatal, perinatal, and maternal mortality: A systematic review and meta-analysis. PLOS ONE, 2015; https://doi.org/10.1371/journal.pone.0139288

13. Kaboré R, Meda IB, Koulidiati JLE, Millogo T, Kouanda S. Factors associated with very early neonatal mortality in Burkina Faso: A matched case-control study. International Journal of Gynecology and Obstetrics, 2016; 135:S93-S97. https://doi.org/10.1016/j.ijgo.2016.08.017

14. Annan, GN, Asiedu Y. Predictors of Neonatal Deaths in Ashanti Region of Ghana: A Cross-Sectional Study. Advances in Public Health, 2018; 1-11. https://doi.org/10.1155/2018/9020914

15. Roy S, Haque MA. Effect of antenatal care and social well-being on early neonatal mortality in Bangladesh. BMC Pregnancy and Childbirth, 2018; 18(1):4-9. https://doi.org/10.1186/s12884-018-2129-y

16. Sankar MJ, Neogi SB, Sharma J, Chauhan M, Srivastava R, Prabhakar PK, Paul VK. State of newborn health in India. Journal of Perinatology, 2016; 36(s3): S3-S8. https://doi.org/10.1038/.jp.2016.183

17. Kamal SMM. What is the association between maternal age and neonatal mortality? An analysis of the 2007 Bangladesh demographic and health survey. Asia-Pacific Journal of Public Health, 2015. https://doi.org/10.1177/1010539511428949

18. Kwarteng AG, Avorgbedor YE. Determinants of under Five Mortality in Ghana; A Logistic Regression Analysis Using Evidence from the Demographic and Health Survey (1988-2014). American Journal of Public Health Research, 2017; 5(3):70-78. https://doi.org/10.12691/ajphr-5-3-4

19. Boaventura MC, Arusyak SVA. Religious affiliation and under-five mortlaity in Mozambique. Journal of Biosocial Science, 2016; 25(3):289-313. https://doi.org/110.1016/j.bbi.2017.04.008

20. Kanmiki EW, Bawah AA, Agorinya I, Achana FS, Awoonor-Williams JK. Socio-economic and demographic determinants of under-five mortality in rural northern Ghana. BMC International Health and Human Rights, 2014; 2:4.

21. Lawn JE, Cousens S, Zupan J. 4 million neonatal deaths: When? Where? Why? The Lancet, 2005; 365(9462): 891-900. https://doi.org/10.1016/S0140-6736(05)71048-5

22. Oestergaard MZ, Inoue M, Yoshida S, Mahanani WR, Gore FM, Cousens S, Mathers CD. Neonatal mortality levels for 193 countries in 2009 with trends since 1990: A systematic analysis of progress, projections, and priorities. PLoS Medicine, 2011; 8: e1001080. https://doi.org/10.1371/journal.pmed.1001080

23. Orsido TT, Asseffa NA, Berheto TM. Predictors of Neonatal mortality in Neonatal intensive care unit at referral Hospital in Southern Ethiopia: A retrospective cohort study. BMC Pregnancy and Childbirth, 2019; 19(1). https://doi.org/10.1186/s12884-019-2227-5

24. Tekelab T, Chojenta C, Smith R, Loxton D. The impact of antenatal care on neonatal mortality in sub-Saharan Africa: A systematic review and meta-analysis. PLOS ONE, 2019; 14(9):e0222566. https://doi.org/10.1371/journal.pone.0222566

25. Welaga P, Moyer CA, Aborigo R, Adongo P, Williams J, Hodgson A, Engmann C. Why Are Babies Dying in the First Month after Birth? A 7Year Study of Neonatal Mortality in Northern Ghana. PLOS ONE, 2013; 8(3). https://doi.org/10.1371/journal.pone.0058924

26. Hsu ST, Hsieh CJ, Chen HW, Jeng SF, Wu HC, Chen MH, Hsieh WS. Nationwide Birth Weight and Gestational Age-specific Neonatal Mortality Rate in Taiwan. Pediatrics and Neonatology, 2015; 56(3): 149-158. https://doi.org/10.1016/j.pedneo.2014.07.006

27. Muhammed G, Kibriaid A, Khanam R, Mitra K, Mahmud A, Begum N, Baqui A. Rates and determinants of neonatal mortality in two rural sub-districts of Sylhet, Bangladesh. Plos One, 2018; https://doi.org/10.1371/journal.pone.0206795

28. Sumankuuro J, Wulifan JK, Angko W, Crockett J, Derbile EK, Ganle JK. Predictors of maternal mortality in Ghana: evidence from the 2017 GMHS Verbal Autopsy data. International Journal of Health Planning \& Management, 2020; 1-20. https://doi.org/10.1002/hpm.3054

29. Ghana Statistical Services. 2020 Population and Housing Census: Press Release on Provisional Results, 2021. Accessed from: https://statsghana.gov.gh/gssmain/storage/img/infobank/2021\%20PHC\%20Provisional\%20Results\%20Press\%20Release.pdf; on November 4, 2021.

30. Ghana Statistical Service. Ghana Living Standard Survey (GLSS 7) 2017. Accra: Ghana Statistical Service, 2018.

31. Ghana Health Service. Ghana Health Service 2016 Annual Report. Accra: Ghana Health service, 2017.

32. Zaka N, Alexander EC, Manikam L, Norman ICF, Akhbari M, Moxon S, Pearson L. Quality improvement initiatives for hospitalised small and sick newborns in low- and middle-income countries: A systematic review. Implementation Science, $2018 ; 13$. https://doi.org/10.1186/s13012-018-0712-2. 
33. Afulani PA. Determinants of stillbirths in Ghana: Does quality of antenatal care matter? BMC Pregnancy and Childbirth, $2016 ; 16(1): 132$. https://doi.org/10.1186/s12884-016-0925-9

34. WHO. WHO Recommendations on antenatal care for a positive pregnancy experience. Geneva: World Health Organisation, 2016.

35. Khoury MJ, Marks JS, McCarthy BJ, Zaro SM. Factors affecting the sex differential in neonatal mortality: The role of respiratory distress syndrome. American Journal of Obstetrics and Gynecology, 1985; 151(6):777-782. https://doi.org/10.1016/0002-9378(85)90518-6

36. Naeye RL, Burt L, Wright DL, Blanc WA, Tatter D. Neonatal mortality, the male disadvantage. Pediatrics, 1971; 48(6): 902-906.

37. WHO. Pregnancy, Childbirth, Postpartum and Newborn Care: A guide for essential practice Third Edition, 2015. Retrieved from www.who.int, on March 1, 2020.

38. De Graft-Johnson J, Vesel L, Rosen HE, Rawlins B, Abwao S, Mazia G, Tekleberhan A. Cross-sectional observational assessment of quality of newbom care immediately after birth in health facilities across six sub-Saharan African countries. BMJ Open, 2017; 7(3). https://doi.org/10.1136/bmjopen-2016-014680

39. Liu L, Oza S, Hogan D, Perin J, Rudan I, Lawn JE, Black RE. Global, regional, and national causes of child mortality in 2000-13, with projections to inform post-2015 priorities: An updated systematic analysis. The Lancet, 2015; 385(9966): 430-440. https://doi.org/10.1016/S0140-6736(14)61698-6

40. Moore ER, Bergman N, Anderson GC, Medley N. Early skin-to-skin contact for mothers and their healthy newborn infants. Cochrane Database of Systematic Reviews, 2016. https://doi.org/10.1002/14651858.CD003519.pub4 